\title{
Report
}

\section{Hysteria Outbreak Investigation in Kombolcha Town Among School Girls, Northwest Ethiopia, January, 2013}

\author{
Mastewal Worku Lake ${ }^{1}$, Mulugeta Mebratu Erku ${ }^{2}$, Hiwot Amara Hailu ${ }^{3}$, Adamu Addise Nuramo ${ }^{4}$ \\ ${ }^{1}$ Amhara Regional State Health Bureau, Public Health Emergency Management Core Process, Bahir Dar, Ethiopia \\ ${ }^{2}$ MSH/SCMS Project - Regional Health Systems Strengthening Unit, Bahir Dar, Ethiopia \\ ${ }^{3}$ Bahirdar Regional Health Research Laboratory Centre, Bahirdar, Ethiopia \\ ${ }^{4}$ Department of Preventive Medicine - Epidemiology Unit, School of Public Health, Addis Ababa University, Addis Ababa, Ethiopia
}

\section{Email address:}

womas01@yahoo.com (M. W. Lake), mmebratu@yahoo.com (M. M. Erku), hiwotamare22@yahoo.com (H. A. Hailu), adamuaddissie@gmail.com (A. A. Nuramo)

\section{To cite this article:}

Mastewal Worku Lake, Mulugeta Mebratu Erku, Hiwot Amara Hailu, Adamu Addise Nuramo. Hysteria Outbreak Investigation in Kombolcha Town Among School Girls, Northwest Ethiopia, January, 2013. Science Journal of Public Health. Vol. 4, No. 1, 2016, pp. 37-42. doi: $10.11648 /$ j.sjph.20160401.15

\begin{abstract}
Hysteria described for more than 600 years in a variety of cultures and settings for significant adverse of public health consequences and economic implications. The aim of this study was to investigate the outbreak, determine possible risk factors and guide intervention measures. In December 25, 2012, district health office notified to Regional Health Bureau about a suspected hysteria outbreak at Kombolcha General primary school. We investigated all 50 cases and compared with 100 matched controls. For the study, detailed discussions were also undertaken with school principal, teachers, students' parents, district health officers and administrators about the event. Then data was analyzed using Epi Info version 7. Fifty cases and no death were identified. The mean age of all cases and controls was 13 with a range 9- 16 year. All were girls, and mostly friends (75\%). The overall attack rate of the cases were 32 per 1000 populations in all age group. Using multivariate analysis, illness were remained as risk factors, perceive evil devil force (Adjusted Odds Ratio (AOR) 5.3 with 95\% CI 2.3-12), psycho stress (AOR) 2.6, 95\% CI 1.14-5.72) and seeing the affected students (AOR) 2.9; 95\% CI 1.1-7.78). Knowledge of modes of transmission illness (AOR) $0.48,95 \%$ CI 0.24-0.96) and separation of girls from the environment at least for 1-2 weeks (AOR) 0.49, (95\% CI 0.22-0.98) were remained as protective factors for the illness. The study confirmed the hysteria outbreak in Kombolcha Town of school girls at General Primary school. And threatening situation was associated with a socio-cultural belief with psycho stress. We recommended conducting immediate reassurance, separate therapy, create community awareness about the illness and counseling at the school could be possible to manage events.
\end{abstract}

Keywords: Hysteria, Primary Schoolgirls, Outbreak, Kombolcha, Ethiopia

\section{Introduction}

Hysteria is a type of psychoneurosis illness but no have organic origin. It described for more than 600 years in a variety of culture and setting. A common manifestation of hysteria is characterized by excitement or anxiety, irrational behavior or beliefs, or inexplicable symptoms of illness in a group of persons [1].

Mass hysteria typically begins when an individual becomes ill hysterical during a period of stress [2]. It is the phenomenon of multiple people experiencing some of the same symptoms, affecting members of a cohesive group, originating from a nervous system disturbance involving excitation, loss or alteration of function. Symptoms of hysteria spread via line-of-sight, sound, or oral communication and spread rapidly for which there is no plausible organic etiology and often occurs down the age-scale and Spread often occurs down the age-scale beginning in older relatively [3].

Mass hysteria occurs most often among the youth, especially preadolescents and adolescents, groups under stress and females disproportionately more than males. Many factors contribute to the formation and spread of hysterical illness: the mass media; rumors; extraordinary anxiety or excitement; 
cultural beliefs and stereotypes; the social and political context; and reinforcing actions by authorities such as politicians, or institutions of social control such as the police or military [4].

Conversion formerly known as hysteria is reflected a psychiatric disorder in the International Statistical Classification of Diseases and Related Health Problems (ICD-10), [5]. The Diagnostic and Statistical Manual of Mental Disorders 4th edition (DSM-IV) specified not have specific diagnosis for Hysteria [6].

Mass hysteria occurred in rare, but usually seen in girls; most common in teenager groups, small, close-knit communities, particularly if they are isolated and enclosed areas such as schools, factories, and hospitals. It also occurred are typical settings more common in rural areas - among uneducated people and in the lower socio-economic classes and generally higher among peoples from minority ethnic groups [7].

From 1973 to 1993, one half of reported outbreaks of psychogenic illness occurred in schools, followed by factories (29 percent), towns and villages (10 percent), families and other institutions [8].

In eighteen up to twentieth century these phenomena have been generally found in mostly factories of industrial country [9]. However, about 60 percent of cases reported in English language literature in the past three decades have occurred in schools. The outbreak of mass psychogenic illness or hysteria was occurred in Great Singapore, New York, Sri Lanka, Afghanistan, Jordan, Tanzania, Mexico City, West Bank and in South Africa were also took place in schools and the majority of cases were females [10].

Mass hysteria has occurred in Malaysia from the 1970s to the 1980s. It affects school-age girls and young women working in factories. The local explanation has been that these girls and young women are affected by "spirits" [11]. In April and May 2010, in Brunei incidents of mass hysteria occurred at two all-girls secondary school students affected by the phenomenon claimed to have been possessed by "spirits" [12].

Incidents also follow an environmental trigger such as an odor and many outbreaks are preceded by illness in an index case that generates a substantial emergency response [13].

In Ethiopia, Epidemic hysteria reported from Gondar city, in north western part of the country in 1982 [14] and Bati town, in north eastern part of the country in 2010 [15].

Ethiopia is a homeland of multinational society with different socio-cultural and presence of vigorous religious beliefs. However, outbreak of hysteria is under reported or not deliberate well across the country. Thus the object of this study was to investigate the outbreak, determine possible risk factors and to take possible intervention measures.

\section{Methodology}

\subsection{Study Area and Population}

On December 25, 2012, we received reports from the
Kombolcha district health office of a suspected hysteria outbreak at Kombolcha General primary school in the Amhara Region of Ethiopia. The region deployed a team of investigators on December 26, 2013 to undertake possible investigations and intervention measures.

Kombolcha Town is located eastern part of Amhara region. The town was located at a distance of $505 \mathrm{KM}$ from the regional town (Bahirdar) and $375 \mathrm{Km}$ from Addis Ababa. The total population of the district is estimated at 104,695 (29,786 Rural and 74,909 Urban) in which females constituted 53287 (51\%) [16].

\subsection{Study Period}

The study was conducted from 26 December 2012- 15 January 2013.

\subsection{Study Design}

Matched Case-control study design was used to identify possible risk factors of illness. Students of neighboring school without signs or symptoms were selected as healthy controls and matched with Sex, age and residence place in the ratio of $1: 2$.

\subsection{Case Definition}

Any person within a teenager exhibiting fainting, hyperventilation, crying loudly, speaking gibberish, unable to move limbs/leg, headache, nausea, dizziness, or a trance-like state or seizure-like movements with in a sudden onset during 26 December 2012-15 January 2013.

\subsection{Data Collection}

Semi-structured questionnaire was used to collect data for case-control study and data was also collected by line listing which was prepared by district health office. Detailed discussions were also undertaken with school principal, teachers, students' parents, district health office and administrators about the event.

\subsection{Environmental Investigation}

The student density per each class, ventilation of the class rooms, the presence of new strain of rules apply on the school, presence of new factories in the surroundings of the school, conflicts and living condition of the families of both cases and controls were carried out. Visual inspection of schools of the cases and controls were also conducted to assess the hygiene, sanitation and living condition of the surrounding of the study groups.

\subsection{Data Analysis}

The data were entered and analyzed using Epi-Info 7 version 7.1.3.0. Used bivariate and multivariate analysis for determined the associated risk factors. The exposure outcome were measured and tested using odd ratio (OR) and 95\% Confidence Interval. 


\subsection{Ethical Issue}

Informed consent was taken from all respondents before interviews and all agreed to take part in the investigation.

\section{Results}

\subsection{Descriptive Investigation}

Fifty cases with no deaths were identified. The mean age of the cases and controls were 13 years with a range 9-16 years. All were female and the majority, 33 (66\%) were Muslims by religious. The overall attack rate of the cases were 32 per 1000 populations in all age group. Age specific attack rate was highest in $\geq 15$ years ( 88 per 1000 population).

The predominant clinical symptoms were headache, dizziness, shout and crying, anxiety, unable to move limbs/falling, fatigue, epigastric pain/cramp, fainting/convulsions, crying loudly, speaking gibberish, and nausea (Table 1). The rate of attack of illness with the majority,
$25(50 \%)$ cases had two - three attacks per a day. The interval time of illness was ranged in 10-30 minute on average 15 minute.

Table 1. Predominate clinical presentation among school girls, Kombolcha Town, Amhara, Ethiopia, 2013.

\begin{tabular}{lll}
\hline \multirow{2}{*}{ Clinical presentation } & Frequency & \\
\cline { 2 - 3 } & Number & Percent \\
\hline Headache & 50 & 100 \\
shout and crying & 50 & 100 \\
Convulsions/fainting & 45 & 90 \\
Nausea & 36 & 72 \\
Epigastric pain and cramp & 33 & 66 \\
Dizziness & 31 & 62 \\
Anxiety & 30 & 60 \\
Hyperventilation & 25 & 50 \\
Fatigue & 25 & 50 \\
Unable to move limbs/falling & 20 & 40 \\
\hline
\end{tabular}

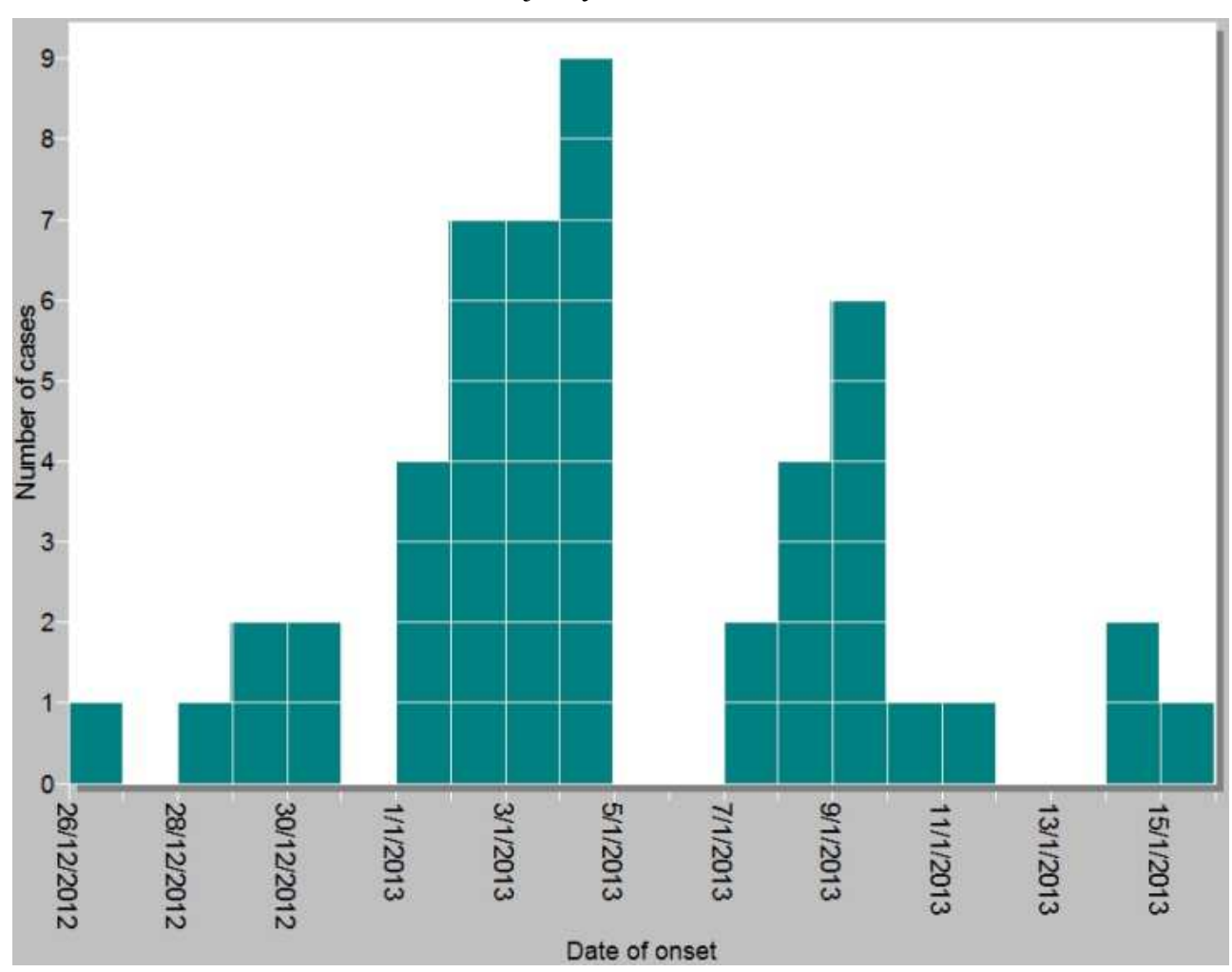

Figure 1. Epidemic curve of hysteria outbreak in Kombolcha General Primary school, Amhara, Ethiopia-January, 2013.

The onset of the outbreak was on 26 of December, 2012, when a 16 years old girl illustrated unidentified symptoms of illness at school. Ten affected students were classmates of the index case. New cases were continued up to January 15, 2013 (figure 1). Most of affected students had peak day (Wednesday and Thursday) and peak time (the break time of 4:30 AM and 9:30AM).

\subsection{Analytical Investigation}

50 cases were compared with 100 matched controls by age, sex and place of residence were included in the case control study. Through bivariate analysis we found that perceive evil devil force (OR 6.6, (95\% CI 3.1-14.1)), psycho stress ( OR 2.1, (95\% CI 1.01-4.35)) were risk factors of illness and knowledge of modes of transmission illness (OR 0.48, 95\% CI 0.24-0.96)), Separate from the school environment for at least $1-2$ weeks (OR 0.49, 95\% CI 0.22-0.98)were preventive factors (Table 2). Through multivariate analysis factors that remained independently risk factors with illness were evil spirits, seeing affected students and knowledge, separate from the school environments were remained as protective factor (Table 3). 
Table 2. Bivariate analysis of trigger factors of hysteria among school girls, Amhara, Ethiopia, 26 December 2012-15 January 2013.

\begin{tabular}{|c|c|c|c|c|c|}
\hline \multirow{2}{*}{ Variable $(n=150)$} & \multicolumn{2}{|c|}{ Possible risk factors and treatments } & \multirow{2}{*}{ Crude OR } & \multicolumn{2}{|l|}{$95 \%$ CI } \\
\hline & Case & control & & Lower & Upper \\
\hline \multicolumn{6}{|c|}{ Perceive Evil- devil force } \\
\hline Yes & 36 & 28 & \multirow{2}{*}{6.6} & \multirow{2}{*}{3.1} & \multirow{2}{*}{14.1} \\
\hline No* & 14 & 72 & & & \\
\hline \multicolumn{6}{|l|}{ Psycho stress } \\
\hline Yes & 31 & 22 & \multirow{2}{*}{4.4} & \multirow{2}{*}{2.14} & \multirow{2}{*}{9.07} \\
\hline No* & 19 & 78 & & & \\
\hline \multicolumn{6}{|c|}{ Seeing the affected student } \\
\hline Yes & 14 & 10 & \multirow{2}{*}{3.5} & \multirow{2}{*}{1.41} & \multirow{2}{*}{8.56} \\
\hline No* & 36 & 90 & & & \\
\hline \multicolumn{6}{|l|}{ Air toxicity } \\
\hline Yes & 4 & 10 & \multirow{2}{*}{0.78} & \multirow{2}{*}{0.23} & \multirow{2}{*}{2.63} \\
\hline No* & 46 & 90 & & & \\
\hline \multicolumn{6}{|c|}{ Food and water poisoning } \\
\hline Yes & 2 & 8 & \multirow{3}{*}{0.47} & \multirow{3}{*}{0.09} & \multirow{2}{*}{2.34} \\
\hline No* & 48 & 92 & & & \\
\hline \multicolumn{4}{|l|}{ Infectious diseases } & & \\
\hline Yes & 1 & 3 & \multirow{3}{*}{0.65} & \multirow{3}{*}{0.07} & 651 \\
\hline No* & 49 & 97 & & & 0.31 \\
\hline unknown & & & & & \\
\hline Yes & 10 & 30 & 058 & 023 & 132 \\
\hline No* & 40 & 70 & 0.58 & 0.23 & 1.32 \\
\hline Knowledge of hyst & & & & & \\
\hline Yes & 10 & 52 & & & \\
\hline No* & 40 & 48 & 0.23 & 0.11 & 0.51 \\
\hline Religious ritual at $\mathrm{t}$ & & & & & \\
\hline Yes & 25 & 22 & 35 & 71 & 734 \\
\hline No* & 15 & 88 & 3.5 & 1.11 & 1.34 \\
\hline psychotherapy & & & & & \\
\hline Yes & 15 & 62 & & 013 & 054 \\
\hline $\mathrm{No}^{*}$ & 35 & 38 & 0.26 & 0.13 & 0.54 \\
\hline Change school & & & & & \\
\hline Yes & 12 & 32 & 067 & 031 & 145 \\
\hline No* & 38 & 68 & 0.01 & 0.31 & $1.4 \mathrm{~J}$ \\
\hline Separate from the $c$ & & & & & \\
\hline Yes & 27 & 83 & 024 & 011 & 051 \\
\hline No* & 23 & 17 & 0.24 & 0.11 & 0.01 \\
\hline
\end{tabular}

Table 3. Multivariate analysis of trigger factors of hysteria, Kombolcha Town, Amhara, Ethiopia, 26 December $2012-15$ January 2013.

\begin{tabular}{|c|c|c|c|c|c|}
\hline \multirow{2}{*}{ Variable $(n=150)$} & \multicolumn{2}{|c|}{ Possible risk factors and treatments } & \multirow{2}{*}{ AOR } & \multicolumn{2}{|c|}{$95 \%$ CI } \\
\hline & Case & control & & Lower & Upper \\
\hline \multicolumn{6}{|c|}{ Perceive Evil- devil force } \\
\hline Yes & 36 & 28 & \multirow{3}{*}{5.2} & \multirow{3}{*}{2.3} & \multirow{3}{*}{12} \\
\hline No* & 14 & 72 & & & \\
\hline \multicolumn{3}{|l|}{ Psycho stress } & & & \\
\hline Yes & 31 & 22 & \multirow{3}{*}{2.6} & \multirow{3}{*}{1.1} & \multirow{3}{*}{5.7} \\
\hline No* & 19 & 78 & & & \\
\hline \multicolumn{3}{|c|}{ Seeing the affected student } & & & \\
\hline Yes & 14 & 10 & \multirow{3}{*}{2.9} & \multirow[t]{3}{*}{1.1} & \multirow[t]{3}{*}{7.8} \\
\hline No* & 36 & 90 & & & \\
\hline \multicolumn{3}{|c|}{ Knowledge of hysteria transmission } & & & \\
\hline Yes & 10 & 52 & \multirow{3}{*}{0.21} & \multirow{3}{*}{0.09} & \multirow{3}{*}{0.49} \\
\hline No* & 40 & 48 & & & \\
\hline \multicolumn{3}{|c|}{ Separate from the environment ( at least 1-2 weeks) } & & & \\
\hline Yes & 27 & 83 & \multirow{2}{*}{0.22} & \multirow{2}{*}{0.1} & \multirow{2}{*}{0.5} \\
\hline No* & 23 & 17 & & & \\
\hline
\end{tabular}

* Reference category

\subsection{Environmental Investigation}

We found student density per class was in average 44 with range 40-50. Seven windows are available for each class with well-ventilated and no unusual odor. Detailed discussion with school principal, teacher, religious leaders and family, they perceived the attributed of the incident to "an evil spirit said 
Satanism items had been discovered around the school" and also another evil devil force was coming from Sudan with voiced affected only school girls.

The spiritual ceremony by religious leaders have been conducted in the school was recognized during our discussion. The barring of pollution in food and water, any tribal or religious conflict and infectious epidemic in the district or neighboring districts was confirmed. Visual inspection of the case and control school structure confirmed similarity of environmental and no any new event happen.

\section{Discussion}

Hysteria outbreak occurred in Kombolcha General primary school. All affected students were females and mostly friends which is common in countries such as Israeli, Tanzania, Mexico City, Sir Lanka, South Africa, Malaysia and New York City [17].

The issue of frequent attack of females in similar outbreaks reported worldwide in various studies. But it couldn't be explained why such outbreaks had been related to females early from ancient Greek thoughts up the modern era [18].

Major symptoms which identified in this outbreak were similar with those outbreaks occurred in Malaysia, Brunei and South Africa [19]. However the frequencies of symptoms for this study were higher, 36 (72\%) of cases respond "evil-devil force" about their perception on factors that triggers the illness. But 14 (28\%) cases replied that seeing another while on attack and thought about the event triggered their illness. This type of spread of symptoms from one to another by watching a person on attack is indicated in different reports [19, 20].

The index case had no any underlying problems and had no conflict with teachers or students but she has had history of similar problem; "evil-devil attack". She also had no any academic problem unlike a Zambian study which found educational problem with below average and emotional problem in an index case prior to the epidemic [21].

Peak cases were seen in January 4, 2013 which days were given group therapy by psychiatric professional; such activities might have increased the number of cases because it contradicted the recommended therapy as separating individual cases [22].

A total of $36(72 \%)$ ] of 50 cases respond "evil-devil force" about their perception on factors that triggers the illness with statically significance. Similar finding (25.0 and 30\%) on evil forces as a root cause was indicated in a study in Taiwan [23]. These beliefs more strengthened during the incident of the event and religious leaders were asked and conducted spiritual ceremony at the school. It supported by another study attributed to the work of evil spirits that the exact trigger and an intervention by traditional or ritual healers is common [24].

Most cases were children with primary education level which fit to a study with South Africa ([20]. The precipitate root cause of Evil devil force, seeing friends and psycho stress with mass psychogenic illness cases were associated with higher rates of the illness. A common manifestation of mass psychogenic illness occurs a group of persons, characterized by irrational behavior or beliefs, or inexplicable symptoms of illness. In our study this finding is a trigger risk factor found that major cause of evil devil force than environmental factor [4].

Separating affected students from school environments for $1-2$ weeks is a protective factor with $\mathrm{AOR}=0.22$ similar study used to prevent measurement reported in Portuguese in the schools [25].

\section{Limitation of the Study}

Absence of laboratory facility at district level, we were not able to collect and analyze quantitative data of environmental samples (Air, Soil, etc.) to rule out some factors to trigger the illness that we suspect in the area.

\section{Conclusion}

We confirmed the hysteria outbreak in Kombolcha Town of school girls at primary school. Most students affected when seeing friends problem, hearing sound, indirect conversation or gossip and communicate each other. Overcrowding of students at school, new strain of rules apply on the school, outbreak of illness and conflict in the area was expelled. The threatening situation overcome associated with a socio-cultural belief with psycho stress.

\section{Recommendation}

A number of recommendations were made. First, strongly create awareness the characters of the illness to the community. Second, immediate reassurance and separate ill from non-ill and from the environment which is the school at least 1-2 weeks. Third, well-timed psychiatric support and provided that counseling in the school. Fourth, further socio-cultural study should be conducted for minimizing challenges to prevent this type outbreak in the school.

\section{References}

[1] http://www.mdhil.com/an-introduction-to-hysteria/ (accessed date 12 January 2013).

[2] Mass, Weir E (2009). "Mass sociogenic illness". CMAJ 172 (2005): 36. Web. 14 Dec. 2009.

[3] Bartholomew, Robert E.; Wessely, Simon (2002). "Protean nature of mass sociogenic illness: From possessed nuns to chemical and biological terrorism fears". British Journal of Psychiatry (Royal College of Psychiatrists) 2002; 180 (4): 300-306.

[4] http://www.acsh.org/healthissues/newsID.155/healthissue_det ail.asp (accessed 10 January, 2013).

[5] World Health Organization (2010). The ICD-10 classification of mental and behavioral disorders. World Health Organization, Geneva, 2010. 
[6] American Psychiatric Association (2012). Diagnostic and Statistical manual of mental disorders. DSM-IV-TR: $4^{\text {th }}$ Edition. American Psychiatric Association; Nov 21, 2012.

[7] http://www.wisegeek.com/what-is-mass-hysteria.htm (accessed 9 January, 2013).

[8] Boss LP (1997). Epidemic hysteria: A review of the published literature. Epidemiol Rev. 1997; Vol.19, No. 2. Pp 233-243.

[9] http://www.las.illinois.edu/news/2009/hysteria/ (accessed date 3 February 2013).

[10] Small, G. W., and J. F. Borus (1983). "Outbreak of Illness in a School Chorus: Toxic Poisoning or Mass Hysteria?" New Eng J of Med, 308, 1983, 632-635. Smith, E. M.

[11] Mass hysteria hits Malaysian school (2001). Asian Economic News (KUALA LUMPUR, July 10). Kyodo. July 16, 2001. Retrieved 9 May 2012.

[12] Bandial, Quratul- Ain (2010). "Mass hysteria: product of 'jinn' or anxiety?" The Brunei Times (BRUNEI-MUARA) May 13th, 2010. Retrieved 9 May 2012.

[13] Selden BS (1989). Adolescent epidemic hysteria presenting as a mass casualty, toxic exposure event. Ann Emerg Med. 1989; 18: 892-5.

[14] Maru M (1982). Epidemic hysteria in Gondar City, Western Ethiopia. East Afr Med J.1982 May; 59(5): 311-3. - accessed from pubmed.

[15] Beyene B (2010). Outbreak of Mass Psychogenic Illness at a High School, Amhara Region, Ethiopia. Int. J. Med. Sci. 2010 April.

[16] Federal Democratic Republic of Ethiopia population Census Commission (2011). Summary and Statiscal Report of the 2007 population and Housing census; population size by age and sex. Addis Ababa, 2011 December 27; page 10.

[17] Benjamin Radford (2012). Mass hysteria in New York school. June, 2012.

[18] Colm Owens, Simon Dein (2006). Conversion disorder: the modern hysteria. Advances in Psychiatric Treatment (2006), vol. 12. Page 154.

[19] Govender I (2010), Mass hysteria among South African primary school learners in Kwa-Dukuza, KwaZulu-Natal. SA Fam Pract 2010; 52(4): 318-321.

[20] Gallay, A, Van Loock, F, Demarest, S, Van der Heyden, JJans, B (2002). Belgian coca-cola-related outbreak: intoxication, mass sociogenic illness, or both. Am. J. Epidemiol. (2002) 155 (2): 140-147.

[21] Manohar Dhadphale, S. P. Shaikh (1983). Epidemic Hysteria in a Zambian School: "The Mysterious Madness of Mwinilunga". Brit. I. Psychiat. (1983), 142, 85-88.

[22] Timothy, F \& Jones, M. D. (2000). Mass Psychogenic Illness: Role of the Individual Physician. Retrieved March 18, 2011, from http://www.aafp.org/afp/20001215/2649.html.

[23] Chen CS, Yen CF, Lin HF, Yang P (2003). Mass hysteria and perceptions of the supernatural among adolescent girl students in Taiwan. J Nerv Ment Dis. 2003 Feb; 191(2): 122-3.

[24] Ruth C. Engs, Richard N. McKaig, and Bruce Jacobs (1996), a Case Study of Mass Hysteria or Toxic Fumes: Considerations for University Administrators. NASPA Journal. Spring 1996; 33(3): 192-201.

[25] De Barros-Ferreira, M (1976). Hysteria and psychosomatic disorders in Portuguese immigrants. PubMed. J. 976 Jul-Aug; 76(4): 551-78. http://www.ncbi.nlm.nih.gov/pubmed/1020687. 